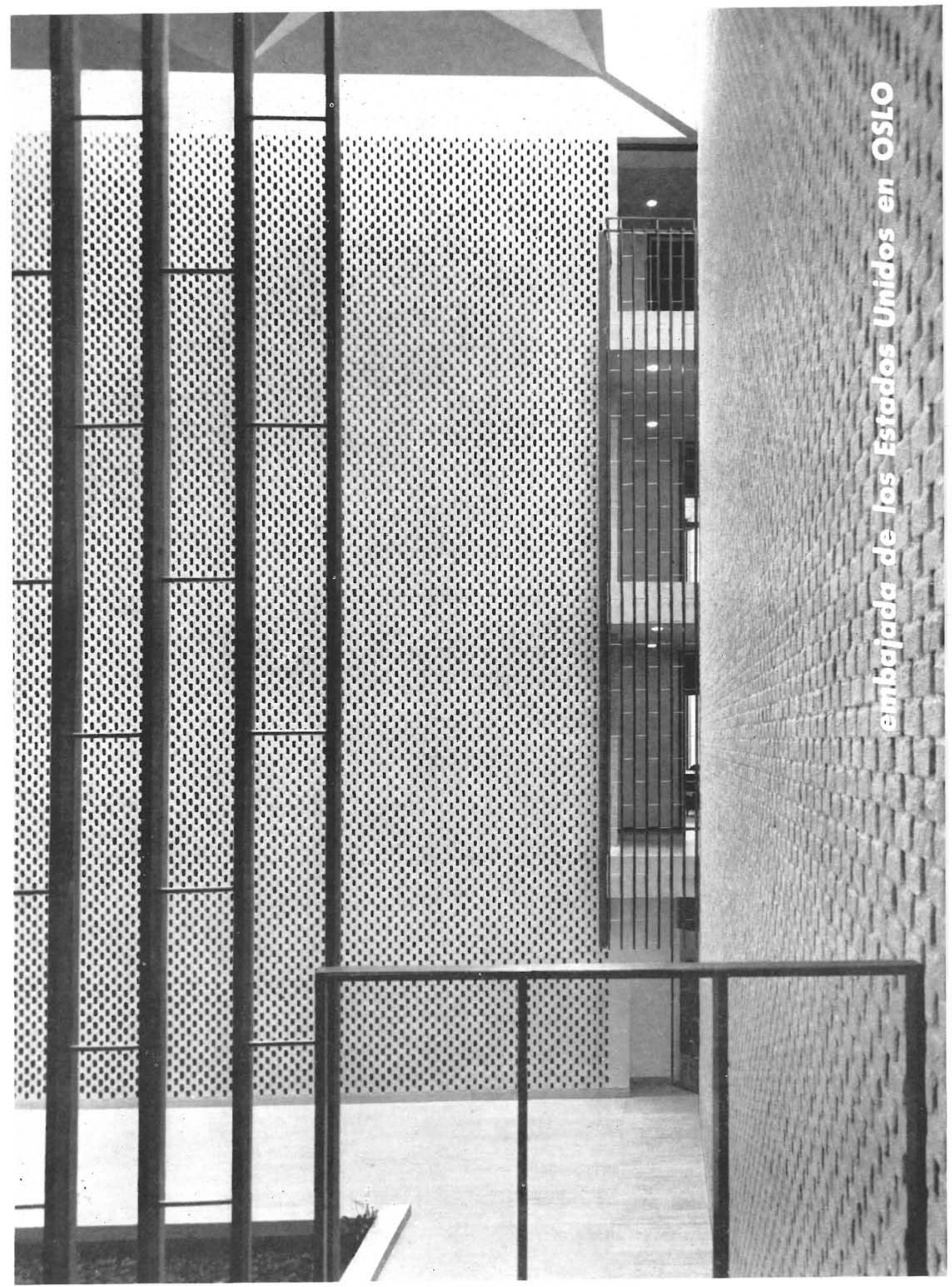




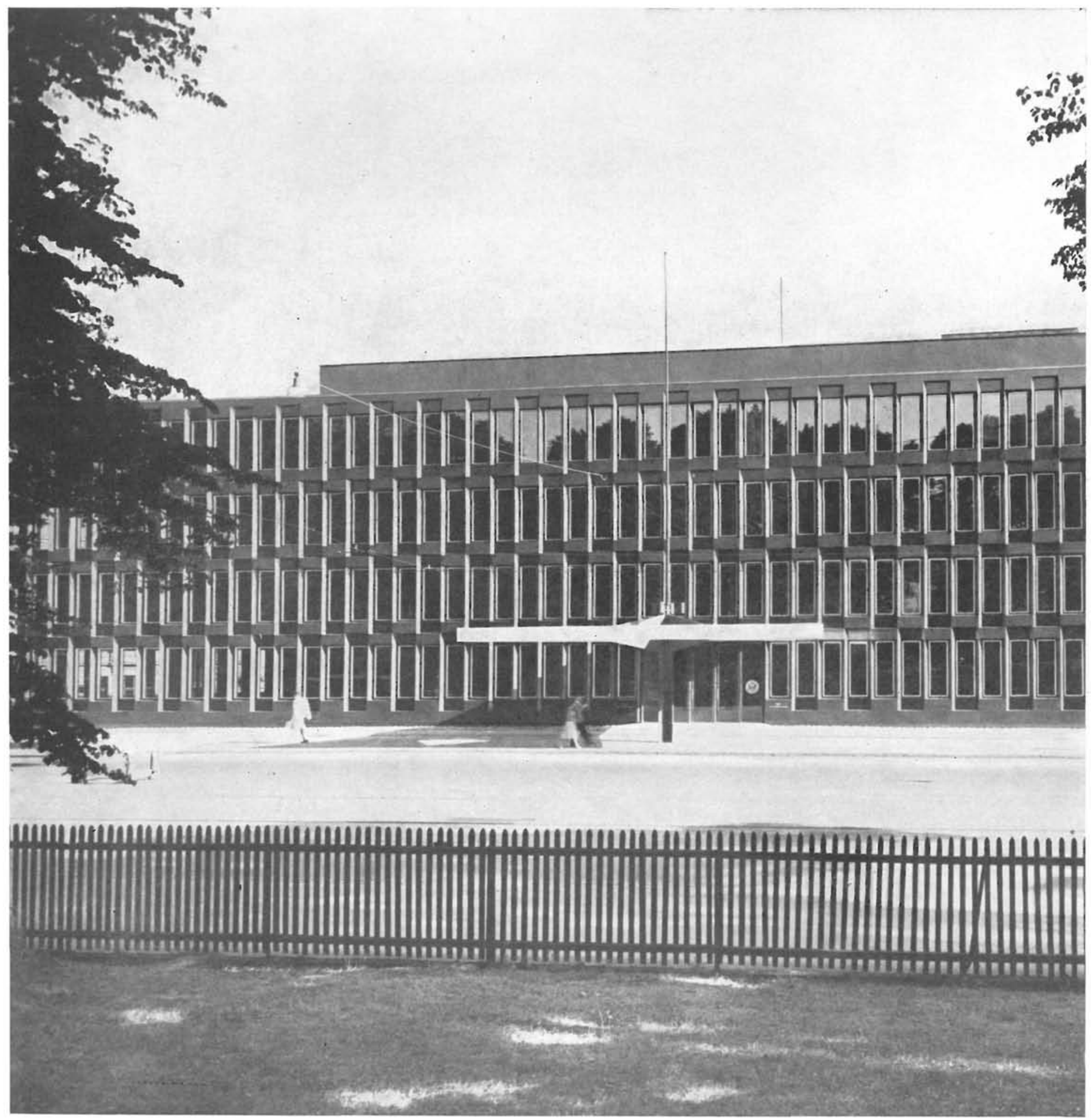

$145-49$

La forma triangular adoptada para el edificio de la Embajada de los EE. UU. en Oslo fue inevitable, ya que el solar disponible (de $600 \mathrm{~m}^{2}$ ) tenía esta planta con calles por los tres lados y fachada principal (de $58 \mathrm{~m}$ ) a la de Drammensveien, frente al Palacio Real, el cual está situado en el centro de un espacioso parque-jardín, con ligera pendiente hacia el edificio.

La calle de Drammensveien presenta una fisonomía uniforme, con fachadas continuas, por lo que parecía importante continuar este ritmo en la nueva construcción, como en efecto se ha hecho, al igual que en los otros dos alzados. 

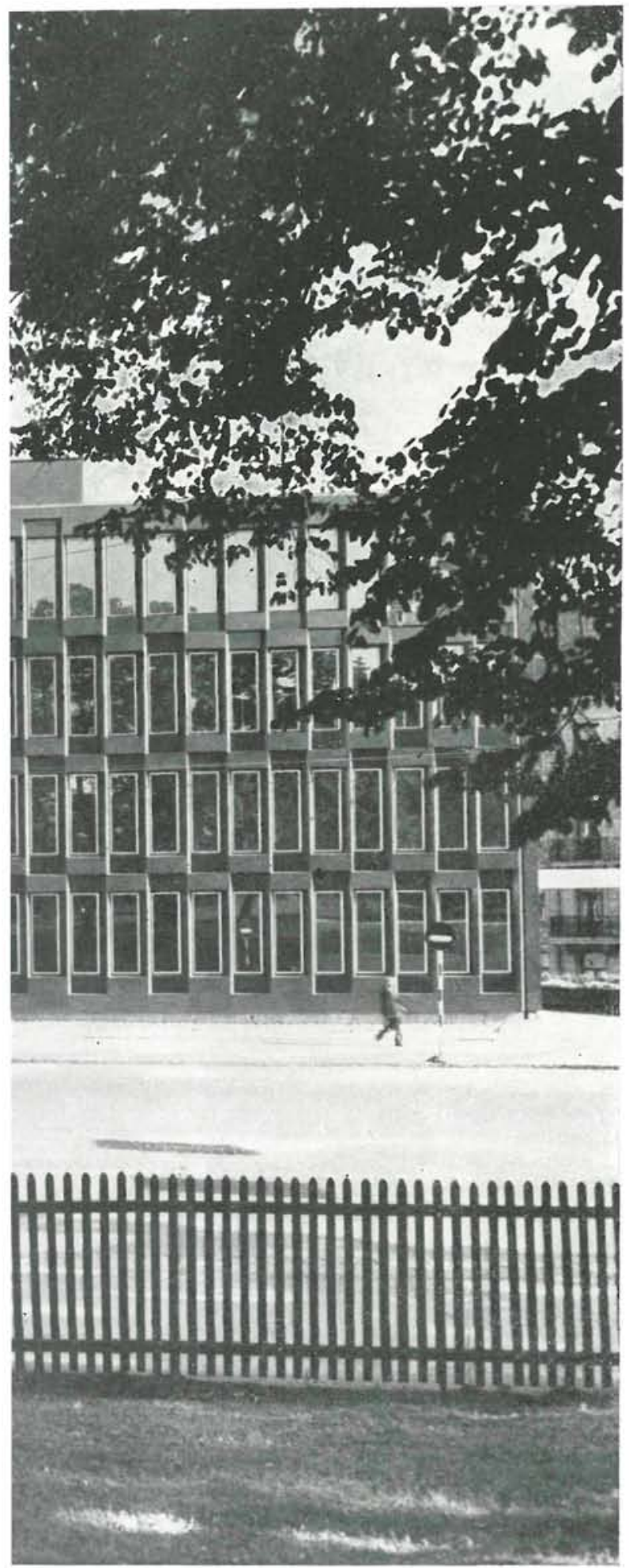

\section{embajada de los Estados Unidos, en OSLO}

EERO SAARINEN Y ASOCIADOS, arquitectos J. ENGH, QUAM Y H. KIAER, arquitectos asociados
En cierto modo, el edificio está inspirado en los palacios triangulares del Renacimiento, con habitaciones alrededor de un patio central. Sin embargo, y por imperativos del clima noruego, parecía necesario cubrir este patio, dándole luz cenital, a través de lucernarios. Por otra carte, como consecuencia del ambiente gris y luvioso de la ciudad, era una sabia medida dotar a este patio de un carácter cólido, grato y alegre, misión encomendada al pavimento de travertino, a los paramentos verticales de madera de teca y a la celosía blanca de ladrillo.

La forma romboidal del patio es una consecuencia lógica de quitar a un triangulo dos de sus vértices, para dedicarlos a escaleras, ascensores y servicios. En el centro de este patio hay un estanque decorativo donde irá seguramente colocado un grupo estárico. I a flumin circunstancia de efecto fisico y psicologico en una ciudad carente de este regalo de la naturaleza durante muchos meses del año.

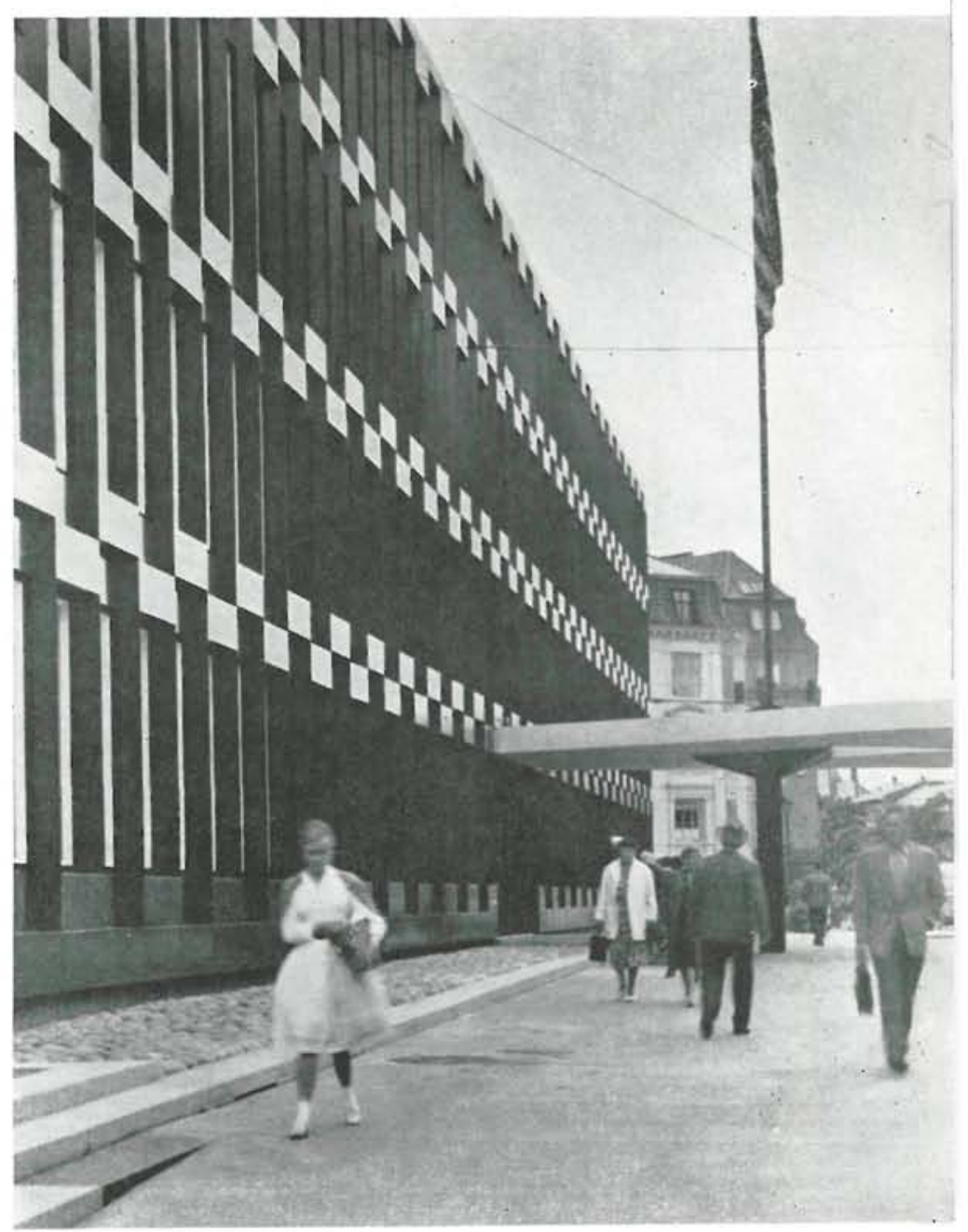



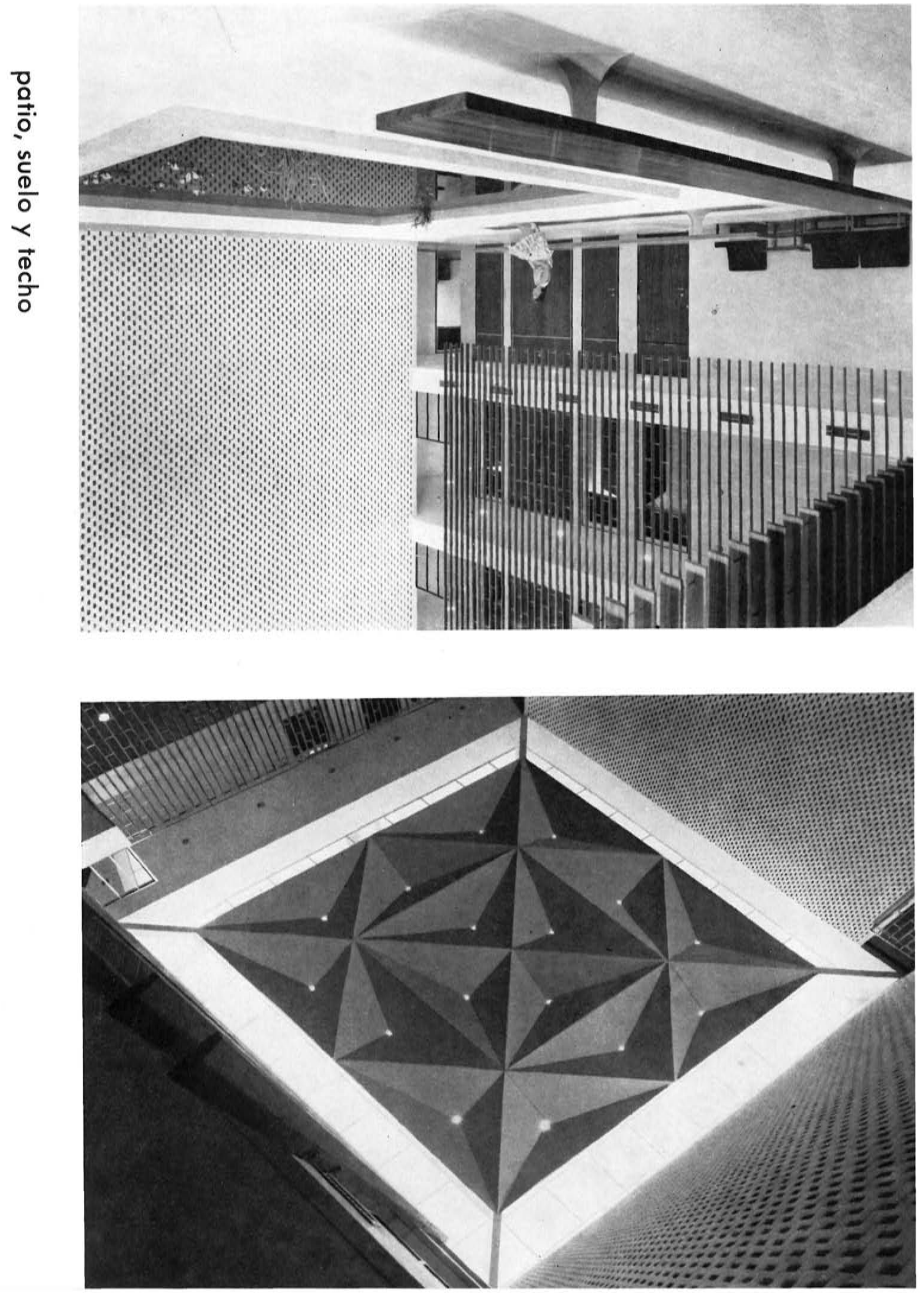


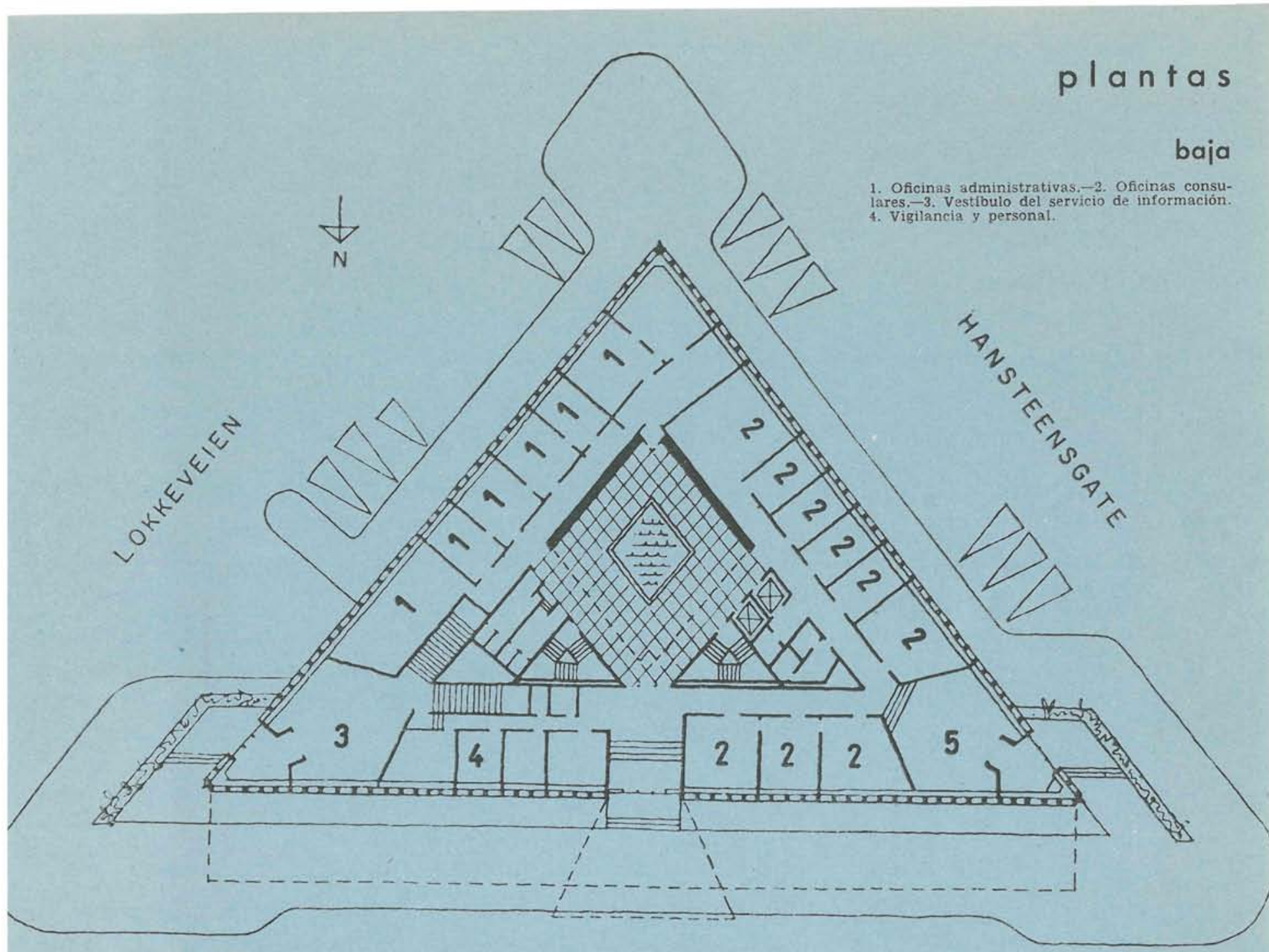

DRAMMENSVEIEN

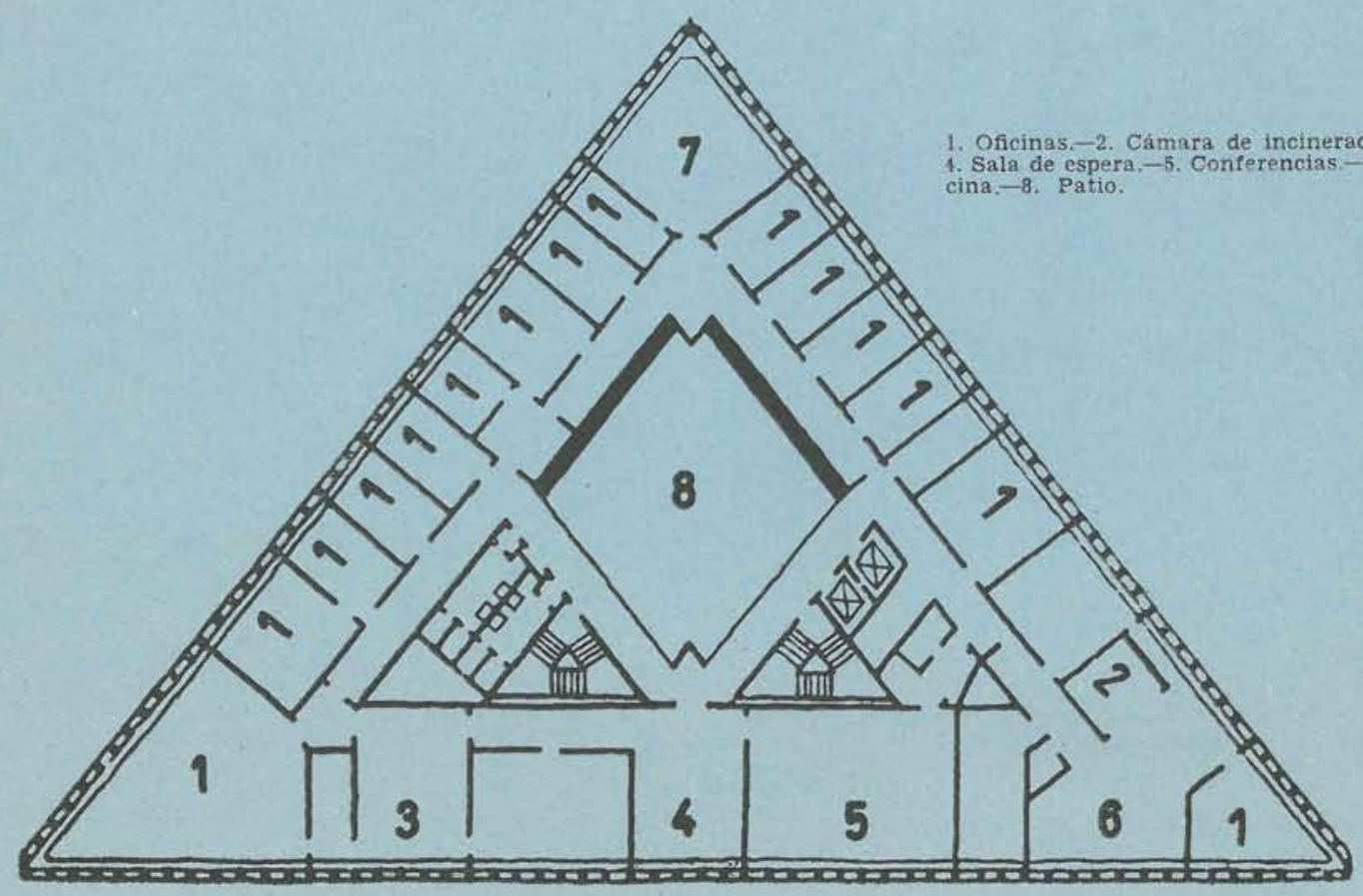

1. Oficinas, -2. Cámara de incineración, -3. Secretaría. 4. Sala de espera, -5 . Conferencias -6 , Registro. -7 . Oft 


\section{detalles constructivos}

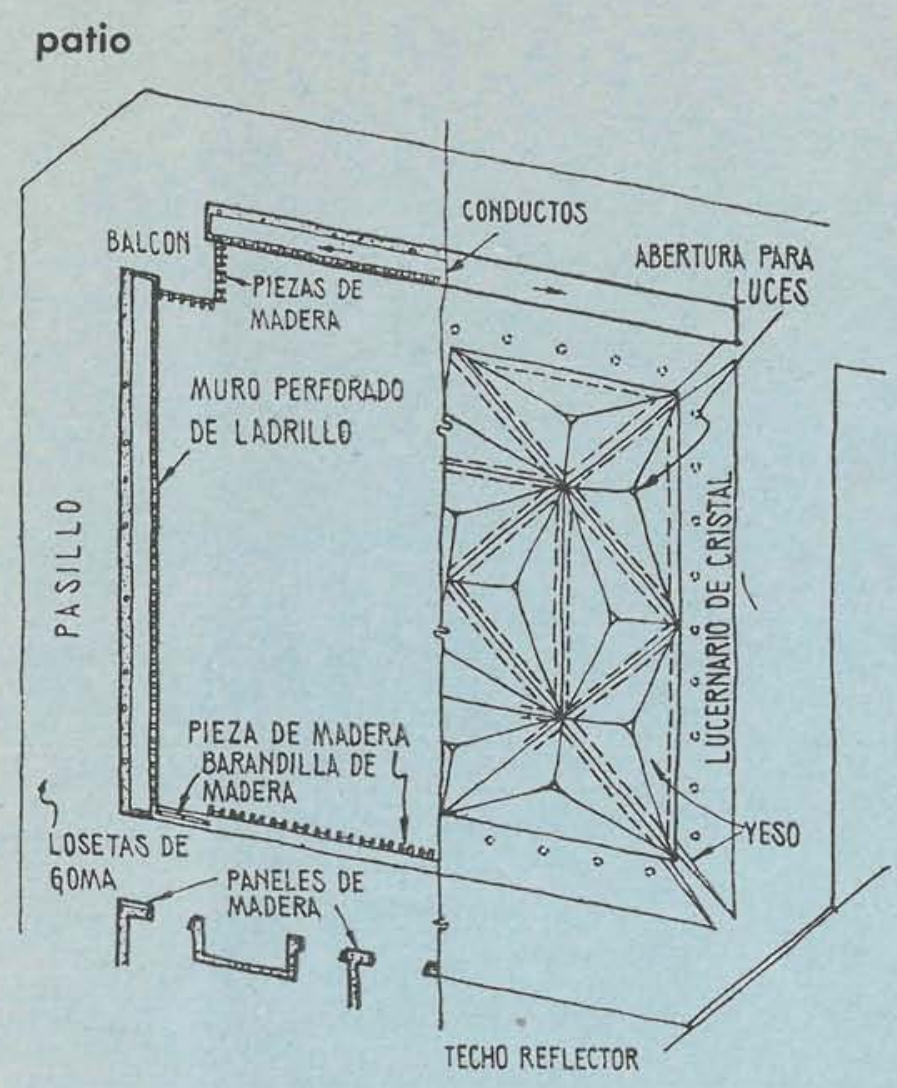

\section{planta y techo}

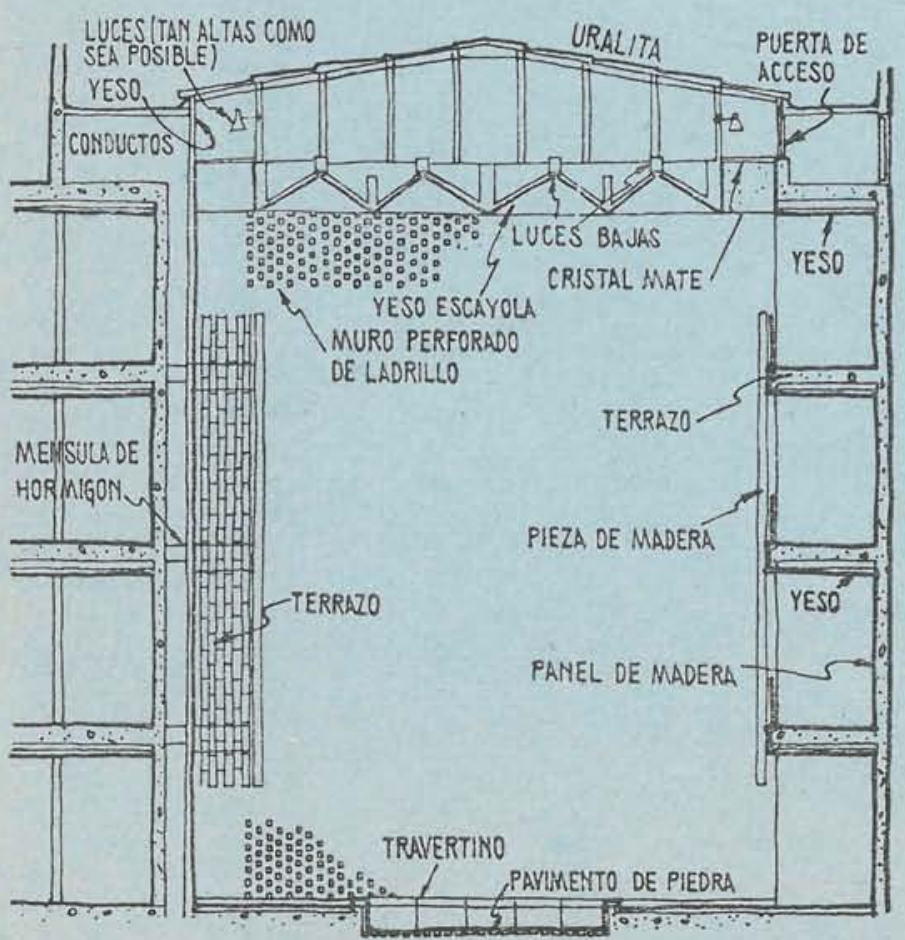

\section{sección transversal}
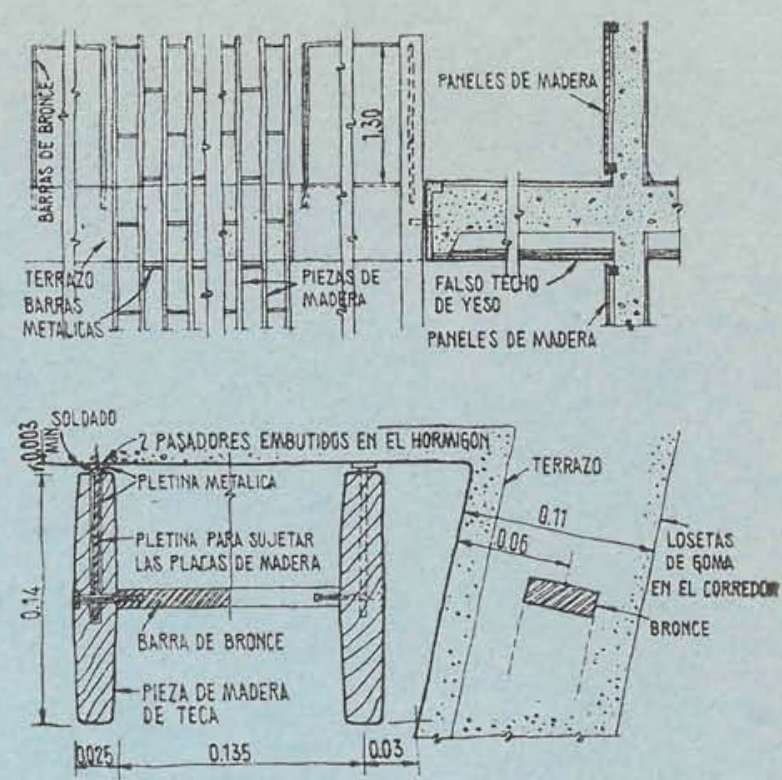

celosía de madera

sección y planta

Las fachadas prefabricadas constituyen una parte muy interesante y conseguida del edificio. La preocupación de los proyectistas consistió en integrar el módulo-base de las oficinas en el sistema estructural, de tal suerte que constituyese un todo uniforme. Las piezas prefabricadas de fachada tienen, en su superficie vista, alrededor de un $90 \%$ de granito noruego esmeralda-perla pulimentado.

Si bien la prefabricación en Noruega va algo retrasada respecto de lo que ocurre, en este aspecto de la técnica, en los vecinos páses-Suecia y Dinamarca - aquí se ha realizado un trabajo soberbio, con la ayuda de personal espelizado un trabajoloseros, císes escandinavos y de Alemacializado de aquellos dos paises escandinavos y de Alema-
nia. Con ello se ha creado un nuevo material de construcnia. Con ello se ha creado un nuevo material de construcción y ha nacido una industria nueva en el país. El granito esmeralda-perla tiene un rico y oscuro color verde, un lustre propio característico y proporciona a la fachada un brillo cambiante, lleno de vitalidad y poco comun en muros prefabricados. La calidad tridimensional dada a las fachadas de la Embajada, derivada de su forma basicaestructural, aumenta ef valor de aquel as ba anotadas. Y así, cuando uno pasea a lo largo de Drammensveien, puede observar cómo estos elementos estructurales realizan un maravilloso, variado y cambiante juego ajedrezado de superficies mates y brillantes, luminosos y oscuros.

En muchos aspectos, el solar era ideal para levantar sobre él una Embajada. Permitió presentar una fachada principal a la arteria más importante de la capital $y$, debido al desnivel descendente entre esta parte y la posterior, pudo darse acceso directo y fácil a los garajes situados en el sótano.

En dicho sótano, se incluyen también: la cafetería y el auditorio, éste situado precisamente debajo del patio y con su misma forma. En la planta baja están emplazadas las secciones Consular y Administrativa, aquélla con entrada independiente por la fachada derecha (respecto de la principal). 

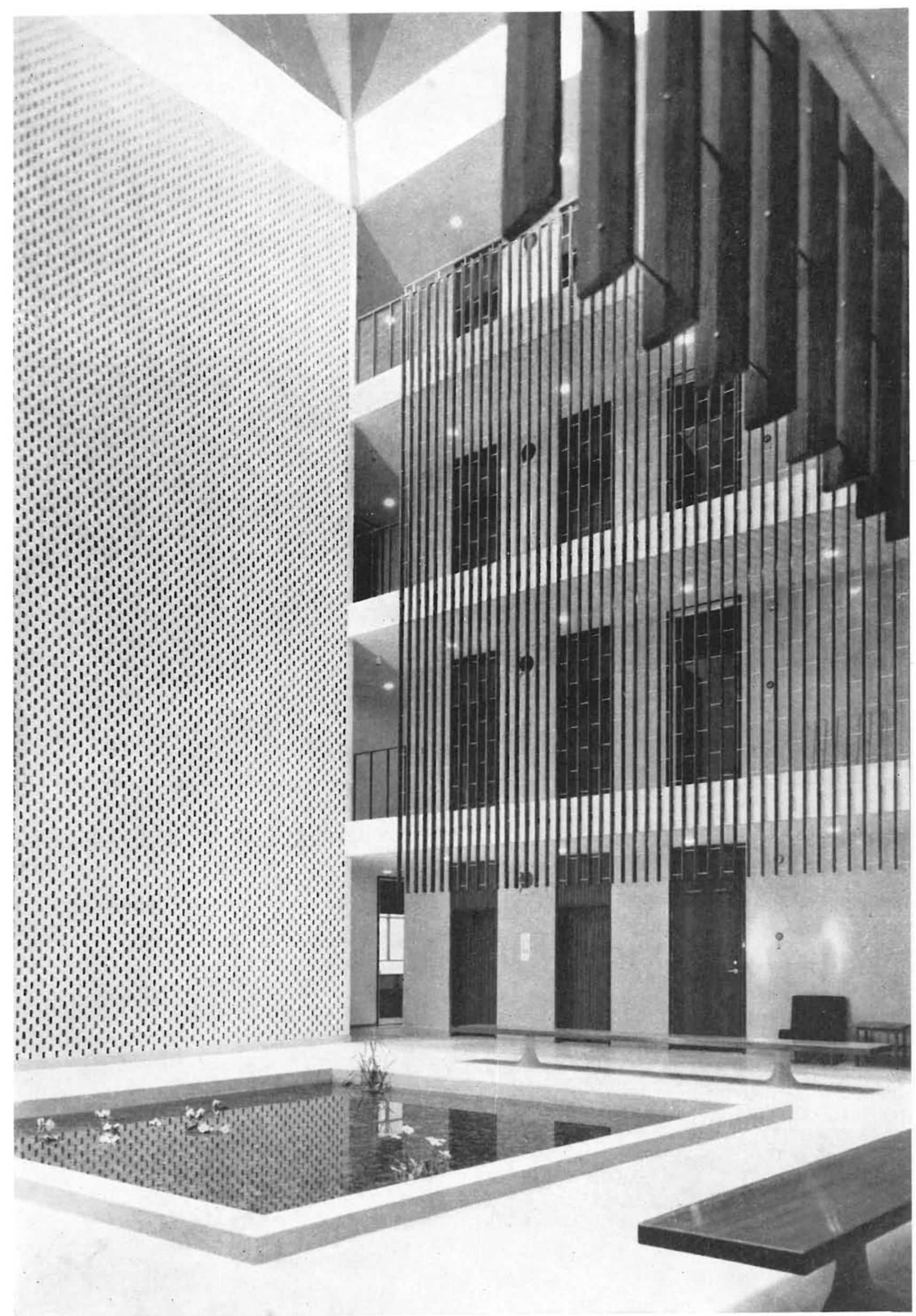
En la parte opuesta se encuentra el Servicio de Información de los EE. UU., con entrada propia, que sirve también para acceder a la biblioteca, la cual, situada en el piso primero y a lo largo de toda la fachada principal, cuando, en la noche, se ve profusamente iluminada desde la calle, invita a la lectura. En esta planta hay, además, otros servicios de información y dependencias culturales. informacion $y$ dependencias culturales. La planta segunda esta reservada a secciones económicas y militares. Finalmente, el ultimo piso alberga la vivienda del Embajador, los servicios políticos y aquellas dependencias de la Embajada que requieren toda clase de precauciones y la máxima reserva.

En la base del mástil de la bandera, sobre el voladizo de la entrada principal, se colocará un magnifico escudo de los EE. UU. en bronce. Los árboles que se plantarán asimismo delante de las dos fachadas laterales, tienden a continuar, en la Embajada, el ritmo ajardinado y verde del palacio real, que se encuentra enfrente.
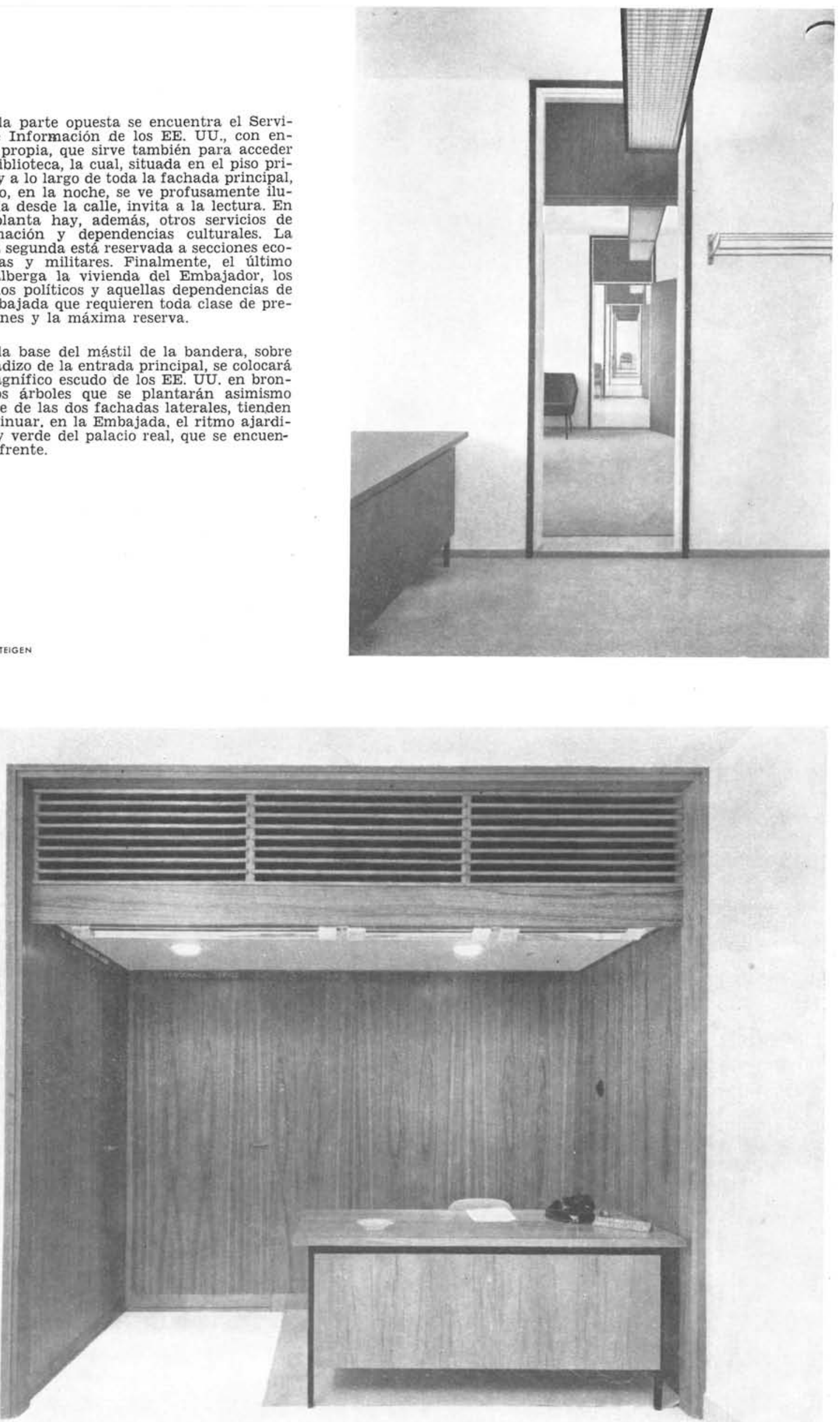